\title{
The Riddle as a Learning and Educational Tool
}

\author{
Hait Shaham ${ }^{1,2}$ \\ ${ }^{1}$ Mathematics department, Beit Berl Academic College, Kfar Saba, Israel \\ ${ }^{2}$ Mathematics department, Gordon Academic College, Haifa, Israel \\ Email: cahit@netvision.net.il
}

Received December 26 ${ }^{\text {th }}, 2012$; revised April $28^{\text {th }}, 2013$; accepted May $9^{\text {th }}, 2013$

\begin{abstract}
Copyright (c) 2013 Hait Shaham. This is an open access article distributed under the Creative Commons Attribution License, which permits unrestricted use, distribution, and reproduction in any medium, provided the original work is properly cited.
\end{abstract}

\begin{abstract}
The primary objective of the present research study is to examine the implications of the implementation of an innovative program for the creation of learning stimulation in a challenging environment, through riddles, on the perception of the learning experience in its different aspects. Previous research studies maintain that in a different learning environment, the students' achievements will be different. One of the goals of the present research study is to examine whether an identical challenging environment creates different or similar results among a population of children with difference in their intelligence level, or in a focused manner, between the achievements of gifted and talented students and students in the traditional learning environment.
\end{abstract}

Keywords: Development of Social Skills; Thinking Styles in the School; Educational Sociology; Gifted; Thinking-Focused Teaching; Riddles; Learning Climate; Motivation to Learn

\section{Introduction}

The present research study, which addresses the topic of changes and innovations in education, sees the importance of the development of a challenging learning environment as developing coping processes (for instance, with a riddle) and enigmatic reality - as a natural and effective way of the assimilation of the development of values and information. Coping with thinking challenges, as with the example of riddles, has steadily been increasing representation in science, society, and the media and it also serves as a basis of the reciprocal activity among people in the different media channels in Israel and around the world (Arbel, 1990).

Many resources have been invested in the past decade in the educational system in Israel in the development of the students' abilities, as well as the integration of technology and computers in the teaching and learning process of many content realms. In spite of these efforts, it appears that the potential is far from being completely exploited.

According to modern educational approaches, teaching must focus on the creation of opportunities for the development of learning abilities through active learning, the development of critical thinking using tasks, and the adjustment of learning styles to thinking styles. The present research study focused on the achievements of students who learned in a challenging learning environment (Hamizer riddles) in two frameworks (traditional class and gifted class, Gordon Center) and thinking styles as a learning strategy. The goal is to develop the learning framework as a predictor of achievements in the challenging learning environment.

\section{The Theoretical Background}

\section{The Gifted and Talented Child}

Both society's reference to the gifted child and the theoreti- cal outlooks regarding his development have experienced farreaching changes in recent years. The researches of Hollingworth (1942), Oden (1968), and Terman (1925) showed that the gifted have characteristics such as maturity, self-image, cognitive independence, and general adjustment, in comparison to non-gifted children.

The concept of "giftedness" has many definitions. Definitions accepted today are qualitative in nature and also include a quantitative element-I.Q. They were first designed at the end of the 1970s and in the beginning of the 1980s by Tannenbaum (1983) and Sternberg (1985). Today, the definitions include a quantitative-statistical-element, the level of innate abilities (measured in intelligence tests), personality abilities, and environmental variables.

Renzulle (1981) and Zorman (1993) describe the gifted child as a curious child who takes the initiative and is possessed of original thinking in problem solving. He has exceptional ideas, expresses himself fluently without obstruction, has a developed and refined sense of humor, is emotionally sensitive, and is aware of his impulsive responses. He is sensitive to beauty and has a developed sense of criticism. He is individualistic, is not willing to accept authority, and is not afraid of being different.

\section{Thinking Styles}

Thinking is a process (influenced by heredity and the environment) that occurs in the mind. It includes the absorption and processing of stimuli. Thinking allows us to supervise our words and deeds and it has different roles in the different stages of teaching and learning. Accordingly, there are different forms of thinking, such as scientific, analytic, creative, etc.

Students differ from one another in their style of thinking. In other words, they differ in the way in which they acquire knowledge, crystallize ideas, feel, and behave. There are sev- 
eral theories that describe a person's different thinking styles. Knowing the person's thinking style (or the profile of thinking styles) may explain why a certain activity suits him and why another one is not appropriate (Zohar, 1996).

The thinking style is the form of thinking that the person prefers in a given situation. The thinking style is the way in which the person chooses to express his thinking (Sternberg \& Wagner, 1991). Hence, the thinking styles are not found in the realm of abilities or realm of personality but in the areas of tangency between them (Sternberg, 1994a).

The fit between the style of thinking and ability is the recipe for success. Every learner has a profile of learning styles and not one single style. A creative learner may be very organized or very scattered, very solitary or sociable. The styles of thinking change from task to task.

Learners are different from one another in the intensity of their preferences. For instance, one learner may insist on working in a group while another is willing to work in a group but does not really want to. Learners are different from one another in the flexibility of their style of thinking. Sometimes the style of thinking is not commensurate with the style of teaching in the school and the learner must evince a degree of flexibility to allow the learning (Sternberg, 1994a).

Sternberg (1997) maintains that it is possible to teach a thinking style and that the thinking style can be measured. To teach how to use a certain thinking style it is necessary to allow the person activities that require him to use this thinking style. When there is fit between the learner's style of thinking and the nature of the task he has been set, the results are the best (Smith, 2002; Sternberg, 1994a). Styles are not fixed and may change over the course of life.

Sternberg (1994b) posited a theory on the question of how people conduct their everyday cognitive activities inside and outside the school. He classifies the styles of thinking into thirteen styles under five categories.

- Function-the learner's mode of operation.

- Forms - the learner's form of activity.

- Levels - the learner's level of coping with the situation or task.

- Scope-the learner's tendency to cope with the task alone or in the group.

- Leaning - the learner's tendency to think independently or perform instructions.

The present research examines patterns of thinking as one of the characteristics in the student's personal world. The present research study made partial use of the model proposed by Sternberg (1994b) and addressed the relevant styles as characteristic of and adjusted to the challenging learning environment (Chamizer riddles). The thinking pattern is the composition of the thinking styles. The students' thinking styles in the present research were examined in a questionnaire, based on the theory of Sternberg (1997), which includes thirteen thinking styles, from which six thinking styles were chosen: executive, internal, external, liberal, conservative, and local. These thinking styles characterize and are adjusted to the learning environment of the “Chamizer Riddles”.

\section{Factors That Influence Thinking Styles}

The person's thinking style is influenced by a number of variables, including culture, and within it the element of the language (Smith, 2002; Sternberg, 1994a). Smith (2002) main- tains that the cultural origin directs to the thinking style, for instance, some countries esteem the individual's success and other countries esteem the success of the shared work of a group of people (Smith, 2002). Hence, the native language (as a characteristic of the cultural origin) constitutes a differentiation between students (those whose native language is Hebrewlocal culture and those whose native language is not Hebrewa non-local culture).

Another factor is the gender. Sternberg (1997) describes a research that examined the difference in the thinking styles between boys and girls. Boys were described as adventurous, with initiative, individualistic, with intention ability and progressive. Girls were described as cautious, dependent, supported, nosy, embarrassed, and obedient. These stereotypes represent predictions more than they represent reality.

To summarize, Sternberg (1997) emphasizes that to create effective learning processes we must provide the learner with a variety of activities and teaching methods so that at least some of the activities or teaching methods will suit his thinking style. Some teaching methods suit a certain teaching style more than another one. The student chooses the thinking style for the situation where he is found. The teacher, according to Sternberg, has an impact on his students' thinking style.

\section{The Student's Perception of the Learning Environment}

The class is the physical and social environment where the child spends his time and where he attempts different experiences. The learning climate addresses the learning atmosphere in the classroom, the norms on the topic of the studies, the students' expectations of success in the studies and their achievement behavior (Bar-El, 1996).

In the classroom framework, social processes and reciprocal activities are created, influenced by many variables, such as characteristics of the physical environment, characteristics of the populations of students and teachers, and organizational characteristics. These variables influence the unique characteristics of the class, such as norms, attitudes towards the learning, democracy, performance of assignments, help, cooperation, interpersonal expectations, cohesion, and patterns of interpersonal communication.

The class learning can be defined, first and foremost, in terms of place, space, and time, when within these aspects the processes of learning and teaching occur (Salomon, 2000b). Fraser and Wohlberg (1981) and Salomon (2000a) focus the learning environment as a main source that influences the students' behavior, their ability to develop critical thinking and self-motivation, and their ability to assume upon themselves responsibility for learning that continues throughout their lives.

The constructivist approach engages in the learning environment primarily in the social process of interaction and participation, and acquisition of meaning in an interactive manner for shared knowledge (Brooks, 2000; Greeno, 1997; Vygotsky, 1962).

The technological development and the structuring of technology in the constructivist class constitute the crowning achievements as a challenging environment (Chamizer challenges method) in education. Technology, as a learning resource, must be included in every program for the re-shaping of schools, since it provides the student and the teachers with access to information and to tools that enable information to be addressed, 
processed, and internalized and thus it facilitates the improvement of the students' achievements.

The research study engages in the constructivist learning environment-the structuring of knowledge using technology as a tool of intellectual sharing (Salomon, 2000a). The basis of the present research is the introduction of challenging learning through the use of the computer and the Internet as technological instrumented. The challenging learning-Chamizer challenges — enables the development of personal skills.

One of the main elements of these skills in the present research is resources management that includes four elements that control sources that are not related directly to thinking (Sternberg, 1985). The resources can be external, internal, and interpersonal. The resources are management of time and learning space, regulation of efforts, learning with peers, and search for help (Garcia \& Pintrich, 1996). As the student believes and masters the resources of the learning-technological environment, social environment, work methods, and understands the requirements, the level of performance in all types of tasks included in the research rises.

The learning environment is greatly influenced by the teacher's support as it was perceived by the students, by the learning climate-conduct of the learning, the social climate-the interpersonal interaction formed among the students themselves and between them and the teachers (Assor, 2001). The dominant argument in the literature is that the class climate is what the student perceives subjectively, so that involvement in the learning process develops (or does not develop) (Anderson, 1982; Huesmann \& Guerra, 1997). The different learning approaches focus on how to inspire the students' curiosity and interest and what are the factors of motivation for learning (Michenbaum, Burland, Gruson, \& Cameron, 1998; Pokay \& Blumenfeld, 1990).

The method of the Chamizer riddles implemented in the present research has the goal of developing thinking in the learner; critical thinking through the encouragement of motivation (emotional element) in the student and the creation of cognitive stimuli. This approach sets new challenges, complicated challenges, which constitute an impetus for the successful implementation of programs for the development of thinking (Pintrich, 1990a, 1990b; Pintrich \& De Groot, 1990). It is expressed in the student's belief that he can do the riddle and he has emotions, expectations, and beliefs that influence his efforts in learning (Ames \& Archer, 1999).

\section{Chamizer Riddles}

Chamizer riddles, unlike familiar riddles, most of which are fashioned around factual knowledge and/or logic, are based on the resources of associative imagination. Thus, by their very definition, everything is right. There are infinite possibilities of solution for every riddle and only one of them was chosen by the riddle master (what he considers best). Therefore, with the Chamizer Riddle every person can set sail to his domains of knowledge, imagination, and association and create a process of search and choice of a new type that ensures products of assimilation and acquisition of knowledge in an unmediated manner.

The Chamizer method creates a unique learning/educational process that combines elements such as teamwork, focus, challenge, competitiveness, steadily increasing interest, enjoyment, and self-motivation, with 'adventurous enthusiasm' and curios- ity. This is an open method, in which creative imagination and associative impetus have a main part in the direction of the process. This method is one of the innovative pedagogies that can be promoted through computer technology, including the collection and organization of information for the study of data.

Salomon (2002a) addressed the changes that occur following different projects (Chamizer Riddles) that are implemented in technology rich environments.

- Intensive use is made of computerization technologies.

- The learning is interactive to a large extent, autonomous, and based on teamwork.

- The scholastic tasks enable the students to engage in a structured and active manner in interdisciplinary and authentic tasks.

- The projects are directed by inquiry learning and self-direction.

- Computerized communication enables near and far information sources to be combined.

At the basis of the method is the learner's experience of success and learning. The student becomes responsible for his success and for the success of the members of his group and of his class. Moreover, the student becomes a teacher and an experience of learning and teaching develops and makes him a partner. He develops strategies of cooperation and learning in harmony. In this method, a shared language of values and behavior ways in the group develops.

To conclude, the primary objective of this research is to examine the implications of the implementation of an innovative program for the creation of learning stimulus in a challenging environment through riddles on the perception of the learning experience in its different aspects. Previous researches maintain that in a different learning environment the students will have different achievements.

The program examined in the present research study was developed by the Intel Corporation with the collaboration of the father of riddles, Mr. Dan Chamizer, and is called "The Chamizer Challenges Method in Education”. This program provides students with activities in original and innovative methods and the learning of broad topics that rely on broad areas of knowledge. This goal includes the following sub-goals:

1) To evaluate the Chamizer challenges method in education as an impetus for cognitive development that crosses the bounds of curriculum as a strategy of thinking-focused teaching in any learning framework. In a more focused manner, the goal is to examine:

- The contribution of the learning environment to the promotion of achievements and motivation among students in the traditional class as well as among gifted and talented students.

- The presence of differences in the achievements of the groups of students.

- The fact that the learning environment mediates between the thinking styles and demographic and personal data and the students' achievements.

2) To evaluate the applicative ability of the model of Sternberg in the learning environments of gifted and talented students and of students who are not gifted.

3) To develop and validate an instrument for the evaluation of the Chamizer challenges method as an enigmatic universal tool (in regards to the students' achievements in the two groups).

4) To examine the intervention of background characteristics, 
learning, and thinking styles as an explanation of the achievements of the students who have experience in the challenging learning environment of the Chamizer challenges method.

\section{The Research Hypotheses}

1) The background characteristics of the students influence their achievements. A difference will be found among the students in their achievements. These differences will be expressed in the comparison among the students according to age, gender, native language, and study framework.

2) The student's style of thinking influences his achievements. A relationship will be found between the degree to which the student uses each one of the thinking styles and the level of his achievements.

3) The student's perception of the learning environment influences his achievements. A relationship will be found between his evaluation of the learning environment (according to all its different elements) and his level of achievements.

4) A relationship will be found between the student's evaluation of the dimensions of the learning environment and the level of expression of the different thinking styles.

5) The background characteristics of students do not influence their evaluation of the learning environment. Hence, differences will not be found among the students in the evaluation of the learning according to age, gender, native language, and learning framework.

6) The relationship between the student's background variables and the styles of thinking that he expresses and his level of achievements will be mediated by his degree of evaluation of the learning environment.

\section{The Research Study}

\section{The Research Objective}

The research objective is to learn about the contribution that the implementation of a learning program based on riddles has on the students' learning experience and achievements. In the present research, the learning program is the Chamizer challenges method in education.

\section{The Research Design}

The research is a quantitative research study, based on a methodology of comparative correlative research, which was performed using a perceptions questionnaire for the measurement of the research variables. The comparison between the populations is performed both in regards to the distribution of the variables and in regards to the strength of the relationships among the variables (Birenbaum, 1993).

\section{The Research Process}

The data were collected from two populations: traditional schools and the Gordon Center (cluster sampling according to the characteristics of the school). A total of 79 students came from traditional schools and 161 students came from the Gordon Center.

The research was conducted in a number of stages:

- Stage 1: The approval for the performance of a research from the school principals was received and later the request was made for the teachers participation (according to the list obtained by the principal).
- Stage 2: On the basis of the researcher's meetings in schools, two schools were chosen from the North region and two schools from the Central region. In parallel, the researcher manages the Gordon Center and therefore diverse courses given to the gifted and talented children were chosen.

- Stage 3: The "Chamizer Challenges” program was implemented in all the schools and in the Gordon Center simultaneously, with the same instructions and directives (both for students and for the accompanying teachers).

- Stage 4: The research instrument was distributed and the data were collected and coded using the SPSS program. The subjects were promised that the questionnaires would be anonymous.

\section{The Research Variables}

1) Independent variables: thinking styles, demographic variables, age, gender, and native language.

2) Dependent variable: achievements in solving problems.

3) Mediated variable: perception of the learning environment.

\section{The Research Instrument}

\section{Thinking Styles Questionnaire}

The questionnaire was developed by Sternberg (1977). The research used six thinking styles proposed by Sternberg, when the content of the statement was adjusted to the different learning environments. The responses range on a Likert scale from 1 to 5 , when 1 is "not at all" and 5 is "most considerably". Content validity was evaluated using an expert (the developer of the Chamizer challenges) to examine the relevance of the thinking styles to the challenging environment (riddles). The reliability was examined and found to be high in all the dimensions (Cronbach's alpha ranges from 0.61 to 0.83 ).

\section{Student's Perception of the Learning Environment Questionnaire}

The questionnaire was developed by Ben Zakan (2000) and found to be reliable in the present research (Cronbach's alpha ranges from 0.56 to 0.85 ). The five elements of the learning environment were taken from the original research of Ben $\mathrm{Za}$ kan.

\section{Findings and Conclusions}

The findings of the quantitative research were presented in two parts. In the first part, descriptive statistics were presented, examining the means and standard deviations and Cronbach's alpha, which confirmed the internal reliability of all the research variables and dimensions. In the second part, statistical analyses were performed, examining the research hypotheses. Pearson correlations examined the relationships between the variables and tests for independent samples examined the differences between the two study frameworks. Multiple regression analyses of the Enter type that examined predictions and stepwise multiple regression analyses were conducted, and paths analysis using the AMOS program were performed to examine the mediating variable. The statistical analyses in the second part examined the following:

1) The relationship between background characteristics and achievements. 
2) The relationship between the perception of the thinking style and the level of achievements.

3) The relationship between the perception of the learning environment and the achievements.

4) The relationship between the thinking style and the evaluation of the learning environment.

5) The relationship between gender, age, and native language and the learning environment.

6) The relationship between the background variables and the thinking style with the mediation of the learning environment.

\section{The Relationship between the Background Characteristics and the Achievements}

As the research hypothesis stated, it was found that the learners of a higher age achieved higher achievements. The speakers of a native language that is not Hebrew attained higher achievements than did those whose native language is Hebrew. A significant difference was not found in the achievements between boys and girls. Hence, as the age rises, the ability to achieve rises (Dagan, 1989; Fried, 1984; Piaget \& Inhelder, 1972).

The native language, especially among immigrants from the countries of the Former Soviet Union, was found to predict achievements in the comparison to the native Hebrew speakers. Levin, Shohami, and Spulsky (2003) explain this finding as characteristic of those from the Former Soviet Union, who come from a culture that cultivates achievements and excellence. Additional research studies (Smith, 2002) support this finding and the empowerment of youth through the cultivation of the learning environment and the creation of conditions for excellence.

Significant differences were found in the achievements of the traditional school frameworks in comparison to the Gordon Center students, whose achievements were lower. The present research study found that the traditional learning framework adopts learning in groups in comparison to the Gordon Center framework, which is characterized by individual learning. Hence, it can be learned that learning in groups increases achievements (Hertz-Lazarovitz, 1997; Rotem \& Peled, 2006; Salomon, 2000b).

\section{The Relationship between Perception of Thinking Styles and Level of Achievements}

As the research hypothesis stated, it was found that there is a positive significant correlation between the local, internal, and liberal patterns of thinking and the students' level of achievements in the entire sample. Among the Gordon Center students, a relationship was not found between the thinking styles and the level of achievements. In other words, the thinking styles do not predict success/achievements among the gifted and talented students while in the traditional schools it was found that as the style is perceived as more local, executive, and liberal, the level of achievements is higher. Hence, it can be understood that the thinking styles in regards to the present research have (partial) abilities to predict success when the conditions of the development of the thinking styles are conditions as described in the school in the traditional environment. On the basis of the findings of Sternberg (1997) and Smith (2002) and in regards to the present research findings, it can be assumed that through the assessment of the thinking styles it will be possible to adjust the type of task to the thinking style and thus increase the chances of success. In the present research, it is possible to present the existence of differences in the thinking patterns regarding the different learning environments (traditional, Gordon Center). However, it is not possible to present clusters of thinking patterns due to the low number of research subjects.

\section{The Relationship between Perception of the Learning Environment and Achievements}

As the research hypothesis stated, it was found that the perception of the learning environment predicts success/ achievements only among the Gordon Center students. A relationship was not found between the learning environment and the traditional learning framework. Zedkiyahu (1998) maintains that this relationship depends on the study subject. The present research study showed another effect, beyond the subject of study: the cultivation of the group of learners-gifted and talented students who receive beyond the regular learning environment an academic learning environment in the Gordon Center. It is possible that this finding contributed to the prediction ability of the perception of the learning environment for the success of the Gordon Center students.

\section{The Relationship between Thinking Style and Assessment of the Learning Environment}

As the hypothesis stated, it was found that as the thinking patterns are characterized by local and liberal styles on a higher level, the perception of the learning is significantly better. Support of the findings is seen in research (Michenbaum et al., 1998; Piaget, in Zorman, 1993; Pokay \& Blumenfeld, 1990). In this context, it can be assumed that motivation (Ames, 1990) from the teaching process is not disconnected from the importance the student attributes to the study topic (content and method) and constitutes a catalyst for the success in the achievement of the goal (Ames \& Archer, 1999; Pintrich \& de Groot, 1990).

\section{The Relationship between Gender, Age, and Native Language and the Learning Environment}

As the hypothesis stated, it was found that the girls assess the learning environment as higher than do the boys, beyond the specific learning environment. Klein, and Weiss (2007) found that women are more attentive, evince higher openness to staff conduct, and tend to involve others more in counsel, problem solving, and decision making. In contrast, men have a greater tendency to make decisions and solve problems individually (egocentrism), share less, and are less attentive to others. While this finding refers to the adult worker population in the work environments, it perhaps can also explain the present research findings.

The child's native language was found to influence the perception of the social climate so that a child whose native language is not Hebrew perceives the social climate as lower than does a child whose native language is Hebrew.

The present research proposes to see the learning environment as the student sees it, in conditions of challenging learning (Chamizer riddles) as a variable that explains success and achievements and mediates between the thinking styles and the students' achievements in the traditional learning environment. The learning environment is empowered in its importance since it has the ability to predict success of gifted and talented stu- 
dents (without mediation ability).

Additional demographic variables were not examined as having the ability to explain the evaluation of the learning environment. In addition, the native language was not explicitly addressed in the literature.

\section{The Relationship between Background Variables and Thinking Style with the Mediation of the Learning Environment}

According to the research hypothesis, it was found that among the students in the traditional schools, the learning environment is a variable the completely mediates the relationship between the thinking styles and the students' achievements. However, the perception of the learning environment does not constitute a mediating variable in the relationship between thinking styles and achievements in the Gordon Center. In the Gordon Center, only the liberal thinking style has impact on the students' achievements. As the liberal style is higher, the achievements are higher. In other words, as the Gordon Center students received challenges with tasks in an innovative, original, and challenging manner, which provide a platform for investigation of new situations that are not unequivocal, challenging the existing situations in a daring and creative way through the inculcation of skills of personal leadership and creation of a toolbox for the coping with challenges of thinking on a high level, their achievements are higher (Krathwohl, Bloom, \& Masia, 1964).

The present research proposes to see the learning environment as the student perceives it, in conditions of challenging learning (Chamizer riddles) as a variable that explains success and achievements and mediates between thinking styles (Sternberg, 1995) and the students' achievements in the traditional learning environment. The learning environment is empowered since it was found to be able to predict the success of gifted and talented students (without mediation ability).

\section{The Research Model-Paths Analysis for the Two Learning Environments}

According to this model, the learning environment mediates the relationship between the thinking styles and the achievements only in traditional schools. The executive, external, and conservative thinking styles lose their impact on the achievements when the learning environment is examined as a mediating variable. In the Gordon Center, in contrast, there is no direct impact of the thinking styles on the achievements, aside from the liberal thinking style. As the liberal style is higher, the achievements are higher. The factor of the learning environment does not mediate this relationship and in essence constitutes the meaningful factor that directly influences the achievements. All the thinking styles aside from the liberal style were not found to influence the achievements directly, a finding that supports the significant impact of the perception of the learning environment that the student experienced on the achievements in the special learning environment of the Gordon Center.

\section{Summary and Conclusion}

The present research found the learning environment to be a variable that completely mediates the relationship between the thinking styles and the students' achievements. The study framework does not constitute a variable that mediates the relationship between thinking styles and achievements in the Gordon Center.

The girls in the present research evaluated the learning environment as higher than did the boys. Among children whose native language is not Hebrew, the social climate was found to be lower than that among children whose native language is Hebrew. However, the perception of the learning environment was found to be a variable that mediates between demographic and personal characteristics and thinking style and achievements/success only among the students in the traditional learning environment.

This finding reflects a phenomenon that should be examined. The reference should be from the very introduction of a pedagogical instrument- the Chamizer riddles, developed by the Intel Corporation for the knowledge industries, when its interest is to develop creative autonomy, critical ability, and broad education - the "thinking class".

The meaning of this thesis, as proposed in the present research study, is that a challenging project has the ability to be generalized in different learning environments (traditional/ Gordon Center for gifted and talented children), under conditions in which the students perceive the learning environment as such that cultivates a social and learning climate, motivation to learn, opportunities for resources management abilities-all with the teacher's support and cultivation of reciprocity and teamwork in the solution of the riddles.

\section{Implications}

\section{Theoretical Implications}

- On the basis of the research findings, it is recommended to conduct a further research to be based on an experimental design with the allocation to two groups (experimental and control).

- It is recommended to represent a more diverse sample to differentiate between sectors of the population that represent elements such as native language, to reinforce the finding in the present research study, the parental education, as predictors of achievements and additional demographic variables that did not arise in the present research.

\section{Practical Implications}

- The present research study found differences in the evaluation of the work environment between students in the traditional schools and students in the Gordon Center. The research findings show lower scores of the Gordon Center students in their perception of the learning environment. This finding necessitates the re-examination of the expectations in regards to the satisfaction of the Gordon Center children so as to enable higher levels of development and achievements. The shaping of the learning environment of the gifted students should allow the opportunity to develop personal traits such as creativity, curiosity, insight, perseverance, imagination, and tolerance, through the development of skills of the cultivation of social awareness in discussions, researches, and surveys, through teamwork.

- The present research study raises the question of what is the appropriate/challenging environment that motivates to success? The awareness of the ability observed in the present research of the students in traditional classes to cope suc- 
cessfully in a challenging environment, as proposed by the program of Intel headed by Dan Chamizer, requires the continued assimilation of such challenging programs in the traditional learning curricula. This recommendation necessitates the training program of role-holders in education to have the ability to lead such projects.

- It is recommended to encourage the participation and involvement outside factors with proven ability to intervene as an instrument of educational development to join the effort. This process needs to lead to the adoption and to the assimilation of the principles upon which the initiative is based, till they become working guidelines.

- It is necessary to create an assimilation program beyond the one-time event so that a program like that of Chamizer and Intel will fit into the school curriculum.

- The accessibility to the learning resources (computers, technology) is a main point. It is necessary to refer to the place of the resources in regards to the desired changes and primarily to the place of modern technology.

- It is necessary to acknowledge the importance of the element of the social climate. The social aspect, which is primary the ability of different individuals in the system to cooperate (students, teachers, principals, parents, and other interested parties) is a main aspect in all that pertains to the promotion of processes of change in the approaches of education and development of the generation of the future.

\section{REFERENCES}

Ames, C. A. (1990). Motivation: what teachers need to know? Teachers College Record, 91, 409-421.

Ames, C., \& Archer, J. (1999). Achievements goals in the classroom: Students' learning and motivations processes. Journal of Educational Psychology, 80, 260-267.

Anderson, C. S. (1982). The research for school climate: A review of the research. Review of Education Research, 52, 368-420. doi:10.3102/00346543052003368

Arbel, B. (1990). Riddles (mathematical) and mathematics. Strong Numbers, Journal for Teaching Mathematics in the Elementary School, Haifa University, Beyt Berl College, The Ministry of Education. (Hebrew)

Assor, A. (2001). Cultivation of internal motivation to learn in the school. In A. Assor, \& A. Kaplan (Eds.), Education of thinking, motivation to learn: New perceptions of motivation, number 20, Jerusalem: The Branco Weiss Institute for the Cultivation of Thinking. (Hebrew)

Bar-El, Z. (1996). Educational psychology. Even Yehuda: Reches Publishing House, Educational Projects Ltd. (Hebrew)

Birenbaum, M. (1993). Who is afraid of a research study? Planning and writing a research proposal and research report in the behavioral sciences. Tel Aviv: University Press Publishing House. (Hebrew)

Brooks, J. G. (2000). Towards the constructivist class: Searching for understanding. Jerusalem: The Branco Weiss Institute for the Cultivation of Thought. (Hebrew)

Dagan, T. (1989). Contribution of the characteristics of background, structure factors, and personal traits to the scholastic achievements in the elementary school. Unpublishing MS Thesis, Tel Aviv. (Hebrew)

Fraser, B. J., \& Walberg, H. J. (1991). Educational environments: Evaluation, antecedents, and consequences. Oxford: Pergamon Press Plc.

Fried, Y. (1984). Jean Piaget: Psychology and method. Tel Aviv: Broadcast University Series, Ministry of Defense. (Hebrew)

Garcia, T., \& Pintrich, P. R. (1996). Assessing students' motivation and learning strategies in the classroom context: The motivated strate- gies for learning questionnaire. In M. Birenbaum, \& F. J. R. C. Dochy (Eds.), Alternatives in assessment of achievements, learning processes and prior knowledge. Dordrecht: Kluwer Academic Publishers, 319-339. doi:10.1007/978-94-011-0657-3 12

Greeno, J. G. (1997). Response: One claims that answer the wrong question. Educational Researcher, 20, 5-17.

Hertz-Lazarowitz, R. (1997). Innovative pedagogy: A collection of articles. Haifa: Haifa University, The Faculty of Education. (Hebrew)

Hollingworth, L. S. (1942). Children above 180 IQ, Stanford-Binet; origin and development. Yonkers, NY: The World Dood Company. doi:10.1037/13574-000

Huesmann, R. L., \& Guerra, N. G. (1997). Children's normative beliefs about aggression and aggressive behavior. Journal of Psychology, 72, 408-419.

Krathwohl, D. R., Bloom, B. S., \& Masia, B. B. (1964). Taxonomy of educational objectives: The classification of educational goals, Handbook II: Affective domain. New York: David Mckay Company Incorporated.

Klein , J., \& Weiss, I. (2007). Towards an integration of intuitive and systematic decision making in education. Journal of Educational Administration, 45, 265-277.

Levin, T., Shohami, A., \& Spulsky, D. (2003). Scholastic achievements of immigrant students: summary of findings and recommendations. http://www.biu.ac.il/hu/lprc/Reports/TalmidimOlim.htm.

Michenbaum, D., Burland, S., Gruson, L., \& Cameron, R. (1998). Meta-cognitive assessment. In S. R. Yussen (Ed.), The growth of reflection in children (pp. 3-30). Orlando: Academic Press, Inc.

Oden, M. H. (1968). The fulfillment of promise: 40-year follow-up of the Terman gifted group. Genetic Psychology Monographs, 77, 3-93.

Piaget, J., \& Inhelder, B. (1972). The psychology of the child. Tel Aviv: Sifriat Poalim Press. (Hebrew)

Pintrich, P. R., \& De Groot, E. V. (1990). Motivational and self-regulated learning components of classroom academic performance. Journal of Educational Psychology, 8, 33-40. doi:10.1037/0022-0663.82.1.33

Pintrich, P. R. (1999a). A process-oriented view of student motivation and cognition. In J. Stark, \& Mets (Eds.), Improving teaching and learning through research: New directions for institutional research (Vol. 57, pp. 65-70). San Francisco: Jossey-Bass.

Pintrich, P. R. (1999b). Student learning and college teaching. In R. E. Young, \& K. E. Eble (Eds.), College teaching and learning, preparing for new commitments: New directions for teaching and learning (Vol. 33, pp. 71-86). San Francisco: Jossey-Bass.

Pokay, P., \& Blumenfeld, P. C. (1990). Predicting achievement early and late in the semester: The role of motivation and use of learning strategies. Journal of Educational Psychology, 82, 41-50. doi:10.1037/0022-0663.82.1.41

Renzulle, J. S. (1981). Psychology and education of gifted. New York: Irvington.

Rotem, A., \& Peled, Y. (2006). Towards the online school. Tel Aviv: Mofet Institute Press. (Hebrew)

Salomon, G. (2000a). Pedagogy and technology: What directs what? Lecture in the Shared Discussion of Academia and the Ministry of Education on the Topic of the Integration between Technology and Pedagogy, 2003. http://construct.haifa.ac.il/ gsalomon/pedagogy.htm

Salomon, G. (2000b). Technology and education in the era of information. Tel Aviv: Haifa University, Zmora Beitan. (Hebrew)

Smith, J. (2002). Learning style: Fashion fad or lever for change? The applications of learning style theory to inclusive curriculum delivery. Innovation in Education and Teaching International, 39, 63-70. doi:10.1080/13558000110102913

Sternberg, R. (1985). Beyond IQ: A triarchic theory of human intelligence. New York: Cambridge University Press.

Sternberg, R. (1994a). Allowing for thinking styles. Educational Leadership, 52, 581-588

Sternberg, R. (1994b). Thinking styles: Theory and assessment at the interface between intelligence and personality. In R. J. Sternberg, \& P. Ruggis (Eds.), Intelligence and personality (pp. 169-187). Cambridge: Cambridge University Press.

Sternberg, R. (1997). Thinking styles. Cambridge: Cambridge Univer- 


\section{H. SHAHAM}

sity Press. doi:10.1017/CBO9780511584152

Sternberg, R. J., \& Wagner, R. (1991). Thinking styles inventory. Tallahassee, FL: Star Mountain Projects, Inc.

Tannenbaum, A. J. (1983). Gifted children. New York: Macmillan.

Terman, L. M. (1925). Mental and physical traits of a thousand gifted children. Stanford, CA: Stanford University Press.

Vygotsky, L. (1962). Thought and language. Cambridge, MA: The I.M.T. Press. doi:10.1037/11193-000

Zedkiyahu, S. (1998). Classroom climate, nature and practice. Jerusa- lem: Ministry of Education and Culture. (Hebrew)

Zohar, E. (1996). To learn, to think, and to learn to think. Jerusalem: The Ministry of Education and the Branco Weiss Institute for the Cultivation of Thinking. (Hebrew)

Zorman, R. (1993). Giftedness. Jerusalem: The Division of the Gifted and Science Loving Youth, The Ministry of Education and Culture. (Hebrew) 